\title{
THE GOVERNANCE OF INFORMATION AND COMMUNICATION
}

\section{TECHNOLOGY*}

\author{
John Weckert \\ Centre for Applied Philosophy and Public Ethics \\ Charles Sturt University \\ Richard Lucas \\ Centre for Applied Philosophy and Public Ethics \\ Australian National University
}

\begin{abstract}
Information and communication technologies (ICT) are ubiquitous but governance in the industry is piecemeal at best. Government regulations and various standards apply to parts of the industry, and professional bodies, the Australian Computer Society (ACS) for example, have some influence on individuals, on professional education and on policies. However, unlike medicine, law, accountancy, or plumbing, there are no regulations concerning who can be employed in ICT. While the ACS and similar professional bodies in other countries can and do have an effect on the industry, given that there is no accreditation or licensing scheme in place for those in ICT, their role is not the same as similar professional organisations in many other professions. The ACS can discipline its members for breaches of its ethical code but that is no barrier to employment and it has no effect on the vast majority of workers in the industry who are not ACS members. It does not follow from this that these professional bodies have no important role to play in the governance of the industry, but it is less formal than in many other professions. As already mentioned, they have input to professional education, to government policy-making, and to industry standards, for software development for example. Additionally they provide codes of ethics and conduct for those in the industry, as well as other information through their publications. These and other activities are designed to improve professionalism in ICT.
\end{abstract}

What this suggests is that much of the governance in ICT is informal. Activities and strategies to improve professionalism, and ethical behaviour in general, are therefore of utmost importance. The three papers in this section all contribute to the discussion of aiding professionalism and ethical conduct.

In the first of these papers "What is an ICT Professional Anyway?" Clive Boughton examines the concepts of a professional and of a profession; concepts easy to use but difficult to define. He takes the original approach of describing various types of people working in the industry, based on his experience, and then considers what it means to be a professional in general. He concludes with a number of suggestions regarding what needs to be done in order for the ICT "profession" to become truly professional.

In the second paper Don Gotterbarn addresses the role of codes of ethics in a profession in detail in "ICT Governance and What to Do About the Toothless Tiger(s): Professional Organizations and Codes of Ethics", as part of his examination of ICT governance more generally. His argument is that there is a middle way between a strict regulation approach to governance on the one hand and the relative powerlessness of ICT professional organisations, what he calls "the vague toothless tiger" approach, on the other. According to Gotterbarn, professional bodies and codes of ethics can have teeth. 
In the final paper in this section, “The Decision Disconnect”, Cecilia Ridgley points out that there are various relationships between ethics and governance and, in particular, explores "the centrality of value systems in the practice of governance in the enterprise”. She argues that there is commonly a disconnect between those governing and the governed. Ridgley develops, explains, and argues for a strategy to overcome this disconnect.

These three papers will, we hope, promote further discussion of some of the important topics within the governance of ICT.

The conference on which this special issue is based was part of a research project supported under Australian Research Council's Linkage Projects funding scheme (project number $\underline{\mathrm{LP} 0560659}$ ), with the Australian Computer Society as the industry partner. 